\title{
Effect of Key Parameters on the Photocatalytic Oxidation of Toluene at Low Concentrations in Air under 254 + 185 nm UV Irradiation
}

\author{
Natalia Quici, ${ }^{\mathrm{a}, \mathrm{b}}$ María L. Vera, ${ }^{\mathrm{a}}$ Hyeok Choi, ${ }^{\mathrm{c}, \#}$ Gianluca Li Puma, ${ }^{\mathrm{d}}$ \\ Dionysios D. Dionysiou, ${ }^{c}$ Marta I. Litter ${ }^{\mathrm{a}, \mathrm{b}, \mathrm{e}}$ and Hugo Destaillats ${ }^{\mathrm{f}, \mathrm{g}}$ \\ ${ }^{a}$ Gerencia Química, Comisión Nacional de Energía Atómica \\ Av. Gral. Paz 1499, 1650 San Martín, Prov. de Buenos Aires, Argentina \\ ${ }^{\mathrm{b}}$ Consejo Nacional de Investigaciones Científicas y Técnicas \\ Buenos Aires, Argentina, \\ ${ }^{\mathrm{c}}$ Department of Civil and Environmental Engineering \\ University of Cincinnati, Cincinnati, Ohio, USA \\ ${ }^{\mathrm{d}}$ Photocatalysis and Photoreaction Engineering \\ Department of Chemical and Environmental Engineering \\ The University of Nottingham \\ Nottingham NG7 2RD, United Kingdom \\ ${ }^{\mathrm{e}}$ Instituto de Investigación e Ingeniería Ambiental \\ Universidad de General San Martín \\ Peatonal Belgrano 3563, 18 piso, 1650 San Martín \\ Prov. de Buenos Aires, Argentina \\ ${ }^{\mathrm{f}}$ Indoor Environment Department \\ Lawrence Berkeley National Laboratory \\ Berkeley, California, USA \\ ${ }^{\mathrm{g}}$ Dept. of Civil, Environmental and Sustainable Engineering \\ Arizona State University, Tempe \\ Arizona, USA. \\ ${ }^{\#}$ Department of Civil Engineering \\ University of Texas \\ Arlington, Texas, USA
}

July 2009

Experimental work was carried out at LBNL under US DOE Contract No. DE-AC02-05CH1 1231. This project was supported by a LBNL's Laboratory Directed R\&D Project (\# 08-103, ID 366088), and by the Agencia Nacional de Promoción Científica y Tecnológica (ANPCyT) project PICT200313-13261 (Argentina). N. Quici thanks CNEA-CONICET for a doctoral fellowship. D.D. Dionysiou acknowledges funding from the National Science Foundation through a CAREER Award (BES0448117) for studies dealing with the synthesis of sol-gel $\mathrm{TiO}_{2}$ materials. 


\section{Effect of Key Parameters on the Photocatalytic Oxidation of Toluene at Low Concentrations in Air under 254 + 185 nm UV Irradiation}

Natalia Quici, ${ }^{\mathrm{a}, \mathrm{b}}$ María L. Vera, ${ }^{\mathrm{a}}$ Hyeok Choi ${ }^{\mathrm{c}, \#}$ Gianluca Li Puma, ${ }^{\mathrm{d}}$
Dionysios D. Dionysiou, ${ }^{\mathrm{c}}$ Marta I. Litter ${ }^{\mathrm{a}, \mathrm{b}, \mathrm{e}}$ and Hugo Destaillats ${ }_{\mathrm{f}, \mathrm{g}^{*}}$

${ }^{a}$ Gerencia Química, Comisión Nacional de Energía Atómica, Av. Gral. Paz 1499, 1650 San Martín, Prov. de Buenos Aires, Argentina.

${ }^{\mathrm{b}}$ Consejo Nacional de Investigaciones Científicas y Técnicas, Buenos Aires, Argentina

${ }^{\mathrm{c}}$ Department of Civil and Environmental Engineering, University of Cincinnati, Cincinnati, Ohio, USA.

d Photocatalysis and Photoreaction Engineering, Department of Chemical and Environmental Engineering, The University of Nottingham, Nottingham NG7 2RD, United Kingdom

${ }^{\mathrm{e}}$ Instituto de Investigación e Ingeniería Ambiental, Universidad de General San Martín, Peatonal Belgrano 3563, 18 piso, 1650 San Martín, Prov. de Buenos Aires, Argentina

${ }^{\mathrm{f}}$ Indoor Environment Department, Lawrence Berkeley National Laboratory, Berkeley, California, USA

${ }^{g}$ Dept. of Civil, Environmental and Sustainable Engineering, Arizona State University, Tempe, Arizona, USA.

${ }^{\#}$ Current address: Department of Civil Engineering, University of Texas, Arlington, Texas, USA

To be submitted to: Applied Catalysis B - Environmental

Keywords: heterogeneous photocatalysis, $\mathrm{TiO}_{2}$, titania, toluene, UVPCO, photocatalytic oxidation, air treatment, indoors.

\footnotetext{
*Corresponding author e-mail: HDestaillats@1bl.gov
} 


\section{Abstract}

The effect of key experimental parameters on the removal of toluene under $254+$ $185 \mathrm{~nm}$ irradiation was investigated using a benchtop photocatalytic flow reactor. Toluene was introduced at low concentrations between 10 and $500 \mathrm{ppbv}$, typical of indoor environments, and reacted on $\mathrm{TiO}_{2}$-coated Raschig rings. Two different $\mathrm{TiO}_{2}$-coated rings were prepared: in one case, by dip-coating using a P25 aqueous suspension and, on the other, using an organic/inorganic sol-gel method that produced thin films of mesoporous anatase. Flow rates in the photoreactor varied between $4 \mathrm{~L} \mathrm{~min}^{-1}$ and $125 \mathrm{~mL} \mathrm{~min}^{-1}$, leading to residence times in the range $100 \mathrm{~ms}<\tau<2 \mathrm{~s}$. For these conditions, toluene removal efficiencies were between 30 and 90\%, indicating that the system did not achieve total conversion in any case. For each air flow rate, the conversion of toluene was significantly higher when the reactor length was $10 \mathrm{~cm}$, as compared with $5 \mathrm{~cm}$; however, only marginal increases in conversions were achieved in the two reactor lengths at equal residence time and different concentration of toluene, suggesting that that the reactor is effectively behaving as an ideal reactor and that the reaction is first-order in the concentration of toluene. Experiments were carried out between 0 and $66 \%$ relative humidity $(\mathrm{RH})$, the fastest reaction rate being observed at moderately low humidity conditions $(10 \% \mathrm{RH})$, with respect to both dry air and higher humidity levels. Formaldehyde was formed as a partial oxidation byproduct at low and at high residence times (240 and $960 \mathrm{~ms}$ ), although higher formaldehyde molar yields (up to 20\%) were observed at low $\tau(240 \mathrm{~ms}$ ) and moderate humidity conditions (10 and 33\%), suggesting that both $\tau$ and $\mathrm{RH}$ can be optimized to reduce the formation of harmful intermediates. Toluene removal efficiency increased with the $\mathrm{TiO}_{2}$ thickness (i.e., mass) until a maximum value of $500 \mathrm{~nm}$, beyond which the removal efficiency decreased. This should be attributed to limitations on the rates of toluene decomposition imposed by radiation transport through the film and/or internal diffusion resistances, which can take place within the porous photocatalytic films. 


\section{Introduction}

Building materials, furnishings and electronic equipment used indoors emit volatile organic compounds (VOCs). These pollutants reduce indoor air quality in residential and commercial buildings, and have been associated to a high incidence of asthma, allergies and building-related symptoms (BRS) $[1,2]$. Air cleaning technologies that rely on UV photocatalytic oxidation (UVPCO) can eliminate VOCs and have the potential to significantly improve indoor air quality and to maintain acceptable pollutant levels with reduced outdoor air supply and concomitant ventilation energy savings. In the US, a total of 5.2 quads of energy are used for heating, cooling, and ventilation, from which $\sim 1$ quad is used for ventilation in the commercial stock [3].

Multiple aspects of $\mathrm{TiO}_{2}$ photocatalytic oxidation of organic compounds in the gas phase have been addressed by a profuse scientific literature over the past 20 years [4-9]. In heterogeneous $\mathrm{TiO}_{2}$ photocatalytic systems, after irradiation of the photocatalyst by UV light, the electron-hole generation takes place:

$\mathrm{TiO}_{2}+\mathrm{hv} \rightarrow \mathrm{h}_{\mathrm{bv}}{ }^{+}+\mathrm{e}_{\mathrm{cb}}^{-}$

The water absorbed at the $\mathrm{TiO}_{2}$ surface acts as an electron donor, leading to $\mathrm{OH}^{\bullet}$ formation:

$\mathrm{h}_{\mathrm{bv}}{ }^{+}+\mathrm{H}_{2} \mathrm{O}\left(\mathrm{OH}^{-}\right) \rightarrow{ }^{\bullet} \mathrm{OH}$

and, if $\mathrm{O}_{2}$ is present, conduction band electrons are captured, inhibiting the deleterious recombination of charge carriers:

$\mathrm{e}_{\mathrm{cb}}{ }^{-}+\mathrm{O}_{2} \rightarrow \mathrm{O}_{2}^{--}$

Hydroxyl radicals can react fast enough with toluene in the gas phase, with a bimolecular rate constant of $\mathrm{k}_{\mathrm{OH}}^{\mathrm{tol}}=0.16 \mathrm{ppbv}^{-1} \mathrm{~s}^{-1}[10]$, and this is the first step leading to the mineralization of the organic compound. 
Recently, a few studies investigated the removal performance of UVPCO at low VOC concentrations comparable to those encountered in buildings [11-15]. With VOC concentrations in the ppbv range, the low catalyst surface coverage led to different kinetics and mechanisms with respect to reactions using high gas phase concentrations (in the ppmv range), and the competition between different VOCs for reactive surface sites was shown to be insignificant. Results from a full-size UVPCO air cleaner prototype, which was sized to meet the requirements of a small office building, indicated that: a) the UVPCO unit was able to reduce VOC concentrations in the $20-80 \%$ range for a wide range of typical indoor pollutants, being more efficient for polar, hydrophilic compounds (e.g., alcohols); b) formation of partial oxidation byproducts was significant, and included indoor pollutants of concern such as formaldehyde and acetaldehyde; and c) the generation of these harmful byproducts could be controlled by post-treatment with sorbent and chemisorbent materials placed downstream of the UVPCO unit $[12,13]$.

In addition to provide efficient abatement of undesired oxidation byproducts, the use of adsorbents or chemisorbents downstream of the UVPCO unit may also allow to perform the photocatalytic oxidation of pollutants under other interesting conditions than those achieved with long-wave UV irradiation of $365 \mathrm{~nm}$. Several studies suggested that photocatalysis using ozone-generating short-wavelength UV light [16-20] or in combination with atmospheric non-thermal plasma [21-24] can be suitable alternatives for indoor air cleaning. These radiation sources present the additional advantage of generating excess ozone, as well as other potentially harmful, reactive species that should be prevented from being introduced into occupied spaces. These compounds can be quantitatively removed from the air stream by a sorbent or chemisorbent bed placed downstream in an integrated air cleaner, thus enhancing the oxidative power of UVPCO while efficiently scavenging its undesired byproducts.

Irradiation at $185+254 \mathrm{~nm}$ is reportedly effective in improving the overall VOC removal efficiency in UVPCO, while minimizing the formation of partially oxidized volatile species and extending the lifetime of the photocatalyst through a more efficient elimination of non-volatile oxidation byproducts from its surface [17-20]. In this case, ozone is formed by photochemical dissociation of $\mathrm{O}_{2}$ molecules at $185 \mathrm{~nm}$, as follows [25]: 


$$
\begin{aligned}
& \mathrm{O}_{2}+\mathrm{hv}(185 \mathrm{~nm}) \rightarrow \mathrm{O}\left({ }^{1} \mathrm{D}\right)+\mathrm{O}\left({ }^{3} \mathrm{P}\right) \\
& \mathrm{O}\left({ }^{1} \mathrm{D}\right)+\mathrm{M} \rightarrow \mathrm{O}\left({ }^{3} \mathrm{P}\right)+\mathrm{M}\left(\mathrm{M}=\mathrm{O}_{2} \text { or } \mathrm{N}_{2}\right) \\
& \mathrm{O}\left({ }^{3} \mathrm{P}\right)+2 \mathrm{O}_{2} \rightarrow \mathrm{O}_{3}+\mathrm{O}_{2}
\end{aligned}
$$

and decomposed by radiation of $254 \mathrm{~nm}$ :

$$
\mathrm{O}_{3}+\mathrm{h} v(254 \mathrm{~nm}) \rightarrow \mathrm{O}_{2}\left({ }^{1} \Delta_{\mathrm{g}}\right)+\mathrm{O}\left({ }^{1} \mathrm{D}\right)
$$

The oxidation rate of toluene with $\mathrm{O}\left({ }^{3} \mathrm{P}\right)$ is fast, with a bimolecular rate constant of $\mathrm{k}^{\mathrm{tol}} \mathrm{O}(3 \mathrm{P})$ $=2.1 \times 10^{-3} \mathrm{ppbv}^{-1} \mathrm{~s}^{-1}[26]$. The lifetime of toluene due to this reaction is likely similar to the short reactor residence time. Due to the generation of ozone in this process, photocatalytic oxidation under $185+254 \mathrm{~nm}$ is often termed $\mathrm{UV} / \mathrm{TiO}_{2} / \mathrm{O}_{3}[17,18-27]$. However, this acronym may be misleading since gas-phase ozonation (i.e., direct oxidation of the VOC molecule by molecular ozone) is a relatively slow reaction for most VOCs. In almost all cases, direct ozonation does not take place during the short residence times typical of UVPCO operation (from hundredths of a second to a few seconds). In particular, that is the case for toluene, the model VOC used in this work, with a low bimolecular reaction rate of $\mathrm{k}^{\mathrm{tol}} \mathrm{O}_{3}=9.9 \times 10^{-12} \mathrm{ppbv}^{-1} \mathrm{~s}^{-1}[28]$.

In addition to the photocatalytic generation of hydroxyl radicals through reaction (2), these oxidants can be generated in the gas phase also by reaction of water vapor with $\mathrm{O}\left({ }^{1} \mathrm{D}\right)$ atoms formed in the photolysis of $\mathrm{O}_{2}$ and $\mathrm{O}_{3}$ at wavelengths lower than $300 \mathrm{~nm}$ :

$$
\mathrm{O}\left({ }^{1} \mathrm{D}\right)+\mathrm{H}_{2} \mathrm{O} \rightarrow 2^{\circ} \mathrm{OH}
$$

by direct photolysis of water vapor: 
$\mathrm{H}_{2} \mathrm{O}+\mathrm{h} v(185 \mathrm{~nm}) \rightarrow \mathrm{H}^{*}+{ }^{\circ} \mathrm{OH}$

or through the formation of $\mathrm{H}_{2} \mathrm{O}_{2}$ and its subsequent photolysis by irradiation of ozone in water with near-UV light $(\lambda>300 \mathrm{~nm})$, which produces $\mathrm{H}_{2} \mathrm{O}_{2}$ quantitatively [29]:

$\mathrm{O}_{3}+\mathrm{h} v+\mathrm{H}_{2} \mathrm{O} \rightarrow \mathrm{H}_{2} \mathrm{O}_{2}+\mathrm{O}_{2}$

$\mathrm{H}_{2} \mathrm{O}_{2}+\mathrm{h} v \rightarrow 2^{\circ} \mathrm{OH}$

Additionally, ozone can capture the photogenerated electrons, either directly [7]:

$\mathrm{e}_{\mathrm{cb}}{ }^{-}+\mathrm{O}_{3} \rightarrow \mathrm{O}^{\circ-}+\mathrm{O}_{2}$

or indirectly, generating an ozonide radical, $\mathrm{O}_{3}{ }^{-}$:

$\mathrm{O}_{2}{ }^{-}+\mathrm{O}_{3} \rightarrow \mathrm{O}_{2}+\mathrm{O}_{3}{ }^{\cdot-}$

At the $\mathrm{TiO}_{2}$ surface, the ozonide radical can split or react with adsorbed water:

$$
\begin{aligned}
& \mathrm{O}_{3}{ }^{\cdot-} \rightarrow \mathrm{O}_{2}+\mathrm{O}^{\bullet-} \\
& \mathrm{O}_{3}{ }^{\cdot-}+\mathrm{H}_{2} \mathrm{O} \rightarrow{ }^{\circ} \mathrm{OH}+\mathrm{HO}^{-}+\mathrm{O}_{2}
\end{aligned}
$$

In this study, we identified key parameters and optimal conditions for the effective removal of toluene, a model hydrophobic air pollutant, at realistically low concentrations in the range of double-digit to a few hundred parts-per-billion (ppbv). This systematic evaluation was performed using a bench-scale plug-flow reactor, with better control of the experimental conditions than that allowed by a full-size equipment. We used a UV lowpressure Hg-lamp with $\lambda_{\max }=254 \mathrm{~nm}$ that also produced secondary emission at $185 \mathrm{~nm}$. Previous reports on the photocatalysis of VOCs under ozone-generating radiation used target pollutant concentrations 1 to 3 orders of magnitude higher than those that could be typically encountered in a building air cleaning system [17,20-30], and experimental conditions leading to unrealistically high $\mathrm{O}_{3}$ concentrations (e.g., 3-15 ppm) [19]. Here, we 
investigated the reaction of toluene in the low ppb range, in conditions that generate $\leq 300$ ppb ozone, analyzing the effect of the residence time and the reactor length on the toluene removal and formaldehyde formation. The effect of the relative humidity and film thickness on the toluene removal efficiency was also studied.

\section{Experimental}

\subsection{Materials}

$\mathrm{TiO}_{2}$ (P25) was provided by Degussa AG, Germany, and used without further purification. Polyoxyethylenesorbitan monooleate (Tween 80, Aldrich), 2-propanol (Fisher), acetic acid (Fisher) and Ti tetraisopropoxide (TTIP, Aldrich) were used to prepare films by sol-gel. Toluene used in the flow reactor (> $99.5 \%$ purity) was from SigmaAldrich. Compressed air (zero quality) and nitrogen was provided by Airgas California. HPLC-quality water (J.T. Baker) was used in the humidification system and in the HPLC analysis. Carbonyl-free acetonitrile (B\&J) was used to extract DNPH $(2,4$ dinitrophenylhydrazine) cartridges and in the HPLC analysis. A calibration curve for the quantification of formaldehyde was prepared using a formaldehyde-DNPH hydrazone standard (Aldrich).

\subsection{Plug-flow reactor and ancillary experimental setup}

The plug-flow reactor used in this study has been previously described [27]. It consisted of a cylindrical quartz tube ( $1 \mathrm{~cm}$ internal diameter) containing a variable number of Raschig rings coated with $\mathrm{TiO}_{2}$. The rings were irradiated by a UV lamp placed parallel to the flow tube at a constant distance of $25 \mathrm{~mm}$. The lamp (UVP model 90-0004-01) emitted principally at $\lambda_{\max }=254 \mathrm{~nm}$, with a secondary emission at $185 \mathrm{~nm}$. Its irradiance, $E_{254}=3.0 \mathrm{~mW} \mathrm{~cm}^{-2}$, was determined at $25 \mathrm{~mm}$ from the source using a calibrated UVP radiometer measuring $254 \mathrm{~nm}$ radiation, positioned at the center of the lamp. Both the quartz flow tube and the lamp were housed in a metallic container provided with a shield to partially cover the lamp and adjust the amount of light used in each experiment. The length of lamp uncovered was similar to the length of the quartz tube containing the photocatalystcoated Raschig rings, allowing adjustments to a variable reactor length. Details of the methods used to prepare the coated Raschig rings are provided below (Section 2.3). 


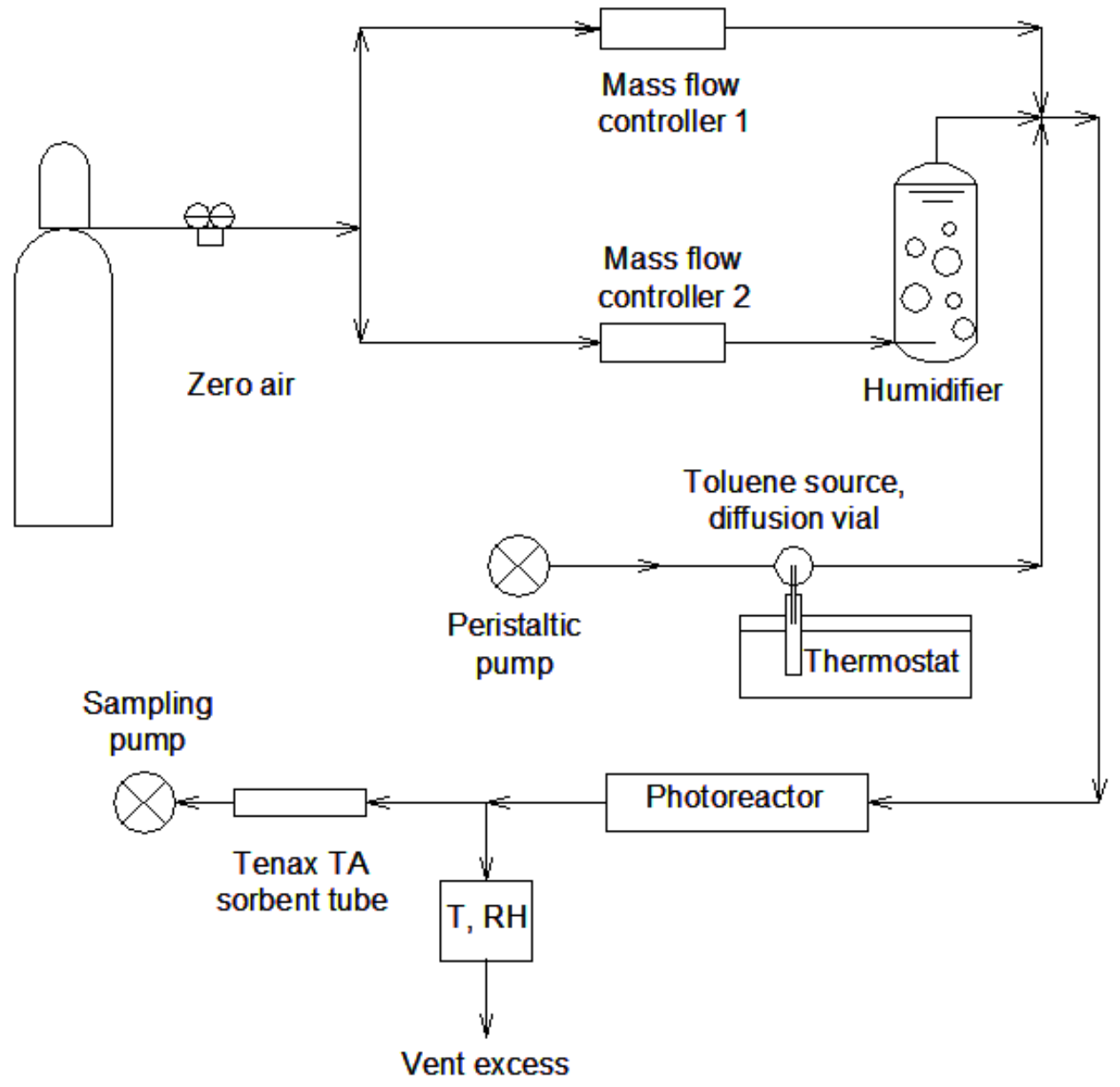

Figure 1. Experimental setup.

The complete experimental setup is illustrated in Figure 1. In each experiment, a constant flow of air (in the range 0.125 to $4 \mathrm{~L} \mathrm{~min}^{-1}$ ) was combined with the flow originated in the toluene source $\left(3 \mathrm{~mL} \mathrm{~min}^{-1}\right)$ upstream of the reactor. The toluene source consisted of a diffusion vial (VICI Metronics, TX) containing the pure liquid, placed in a thermostatic bath at room temperature $\left(25^{\circ} \mathrm{C}\right)$. Concentrations of toluene obtained after dilution with air were in the range $15-480 \mathrm{ppbv}$. The air flow was divided into two streams, one connected directly to the reactor (i.e., dry air flow) and the other saturated with water by bubbling in a humidifier bottle. The flow of each of these air streams was adjusted using mass flow controllers to obtain the desired relative humidity and total air flow, and were measured with a calibrated flowmeter (Dry Cal, BIOS Int.).

Temperature and relative humidity $(\mathrm{RH})$ were monitored continuously inside a secondary chamber placed downstream of the reactor, using a HOBO datalogger (Onset 
Corp.). The concentration of ozone was measured during periods in which sorbent tubes samples were not collected (see section 2.5., below), using a photometric detector (API Model 400).

\section{3. $\quad$ Preparation of photocatalyst-coated Raschig rings}

Two different $\mathrm{TiO}_{2}$-coated Raschig rings were used in this study. The physicochemical characterization of each coated material is provided in Table 1.

Table 1. Physicochemical properties of $\mathrm{TiO}_{2}$ coatings

\begin{tabular}{ccc}
\hline \hline Parameter & P25 $^{\mathbf{a}}$ & Sol-gel $^{\mathbf{b}}$ \\
\hline BET surface area $\left(\mathrm{m}^{2} \mathrm{~g}^{-1}\right)$ & 60.7 & 147 \\
Pore volume $\left(\mathrm{cm}^{3} \mathrm{~g}^{-1}\right)$ & 0.31 & 0.22 \\
Porosity $(\%)$ & n.d. & 46 \\
Average pore size $(\mathrm{nm})$ & 20.5 & 5 \\
Crystalline phase & Anatase $80 \% /$ rutile $20 \%$ & Anatase \\
Crystallite size (nm) & 17.4 & 9 \\
\hline${ }^{\mathrm{a}}$ Determined for P25 powder [31] & & \\
${ }^{\mathrm{b}}$ From ref. [32] & &
\end{tabular}

a) P25 films obtained by a dip-coating method: rings with internal diameter of $4 \mathrm{~mm}$, external diameter of $6 \mathrm{~mm}$ and $20 \mathrm{~mm}$ length were frosted prior to the dipcoating procedure. The rings were immersed in a $5 \% \mathrm{~m} / \mathrm{V} \mathrm{TiO}{ }_{2}$ aqueous suspension at $\mathrm{pH} 2.5\left(\mathrm{HClO}_{4}\right)$, and dip-coated at a rate of $3 \mathrm{~mm} \mathrm{~s}^{-1}$; then, the coated rings were dried in an oven for $24 \mathrm{~h}$ at $130{ }^{\circ} \mathrm{C}$, and the process was repeated three times. The amount of $\mathrm{TiO}_{2}$ deposited on the rings was $500 \mu \mathrm{g} \mathrm{cm}^{-2}$, as measured by mass difference before and after coating. The rings were calcined for $2 \mathrm{~h}$ at $450{ }^{\circ} \mathrm{C}$ at a $7.5^{\circ} \mathrm{C} \mathrm{min}-1$ heating rate [33]. These rings were used in the study of the effect of residence time and of relative humidity.

b) Anatase films obtained by a sol-gel method: rings with internal diameter of $4 \mathrm{~mm}$, external diameter of $5 \mathrm{~mm}$ and $5 \mathrm{~mm}$ length were prepared by dipping at $12.8 \mathrm{~cm} \mathrm{~min}^{-1}$ in a titania sol, following a method described previously [32]. The 
organic/inorganic sol was prepared by dissolving Tween 80 in 2-propanol, which was esterified by addition of acetic acid. The titania precursor TTIP was added under vigorous stirring, in the molar ratio Tween 80:2-propanol:acetic acid:TTIP 1:45:6:1. Films were dried at room temperature for $1 \mathrm{~h}$ and calcined at a rate of $3{ }^{\circ} \mathrm{C}$ $\min ^{-1}$ up to $500{ }^{\circ} \mathrm{C}$. That temperature was maintained for $15 \mathrm{~min}$. Five different ring batches were prepared, by repeating this procedure 1, 3, 5, 7 and 9 times, thus obtaining the film thicknesses reported in Table 2. These five different samples were used to investigate the dependence of photocatalytic efficiency on that parameter. Film thickness was determined by environmental scanning electron microscopy (ESEM Philips XL 30). Figure 2 shows ESEM images corresponding to the cross section of the $\mathrm{TiO}_{2}$ thin film immobilized onto the glass substrate. In the photographs it can be seen that there is a uniform $\mathrm{TiO}_{2}$ layer when the thickness is around $350 \mathrm{~nm}$ (after 3 coatings). The mass of anatase incorporated was estimated using the film porosity and thickness determined experimentally.

Table 2. Samples prepared for the study of film thickness by a sol-gel method.

\begin{tabular}{|c|c|c|c|c|c|}
\hline Number of coatings & 1 & 3 & 5 & 7 & 9 \\
\hline Film thickness (nm) & $100 \pm 35$ & $230 \pm 55$ & $350 \pm 70$ & $500 \pm 45$ & $635 \pm 55$ \\
\hline $\mathrm{TiO}_{2}$ mass $\left(\mathrm{mg} \mathrm{cm}{ }^{-2}\right)$ & $20 \pm 7$ & $50 \pm 12$ & $72 \pm 14$ & $96 \pm 12$ & $119 \pm 15$ \\
\hline
\end{tabular}

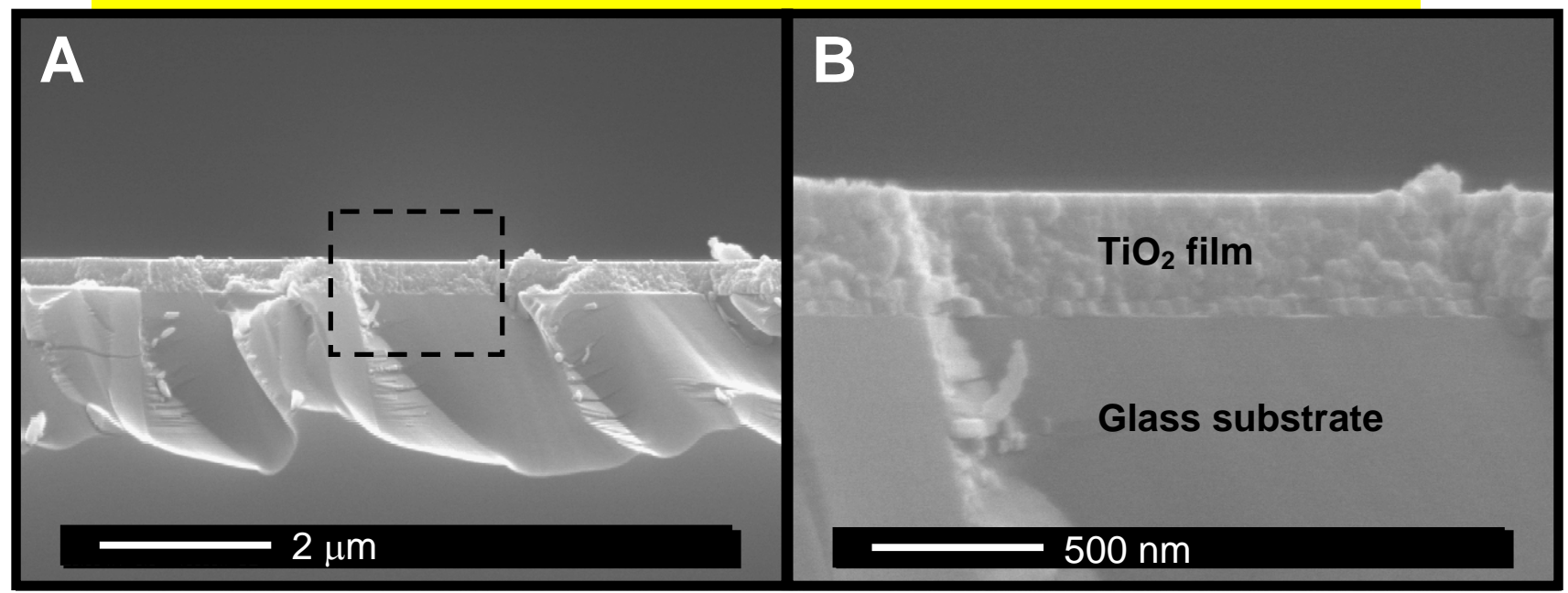

Figure 2. ESEM images of the $\mathrm{TiO}_{2}$ thin film cross section (sol-gel coating, $350 \mathrm{~nm}$ thickness). A) with $2 \mu \mathrm{m}$ resolution (zoom area indicated with a box); B) with $500 \mathrm{~nm}$ resolution. 


\subsection{Irradiation experiments}

Individual experiments comprised three phases. In the first one, with the UV lamp off, the air flow containing toluene was allowed to circulate for a minimum of 30 minutes to establish the adsorption equilibrium with the catalyst. Due to the low toluene concentrations, coverage of the catalyst was at the sub-monolayer level [34]. At the end of this initial period, the toluene initial steady-state concentration was determined by collecting three sequential samples. After turning on the UV lamp, a second period of 30 min allowed the reaction to proceed and reach a second steady-state regime, under continuous irradiation. Three consecutive toluene samples were collected after 30 minutes of irradiation, to determine the new toluene concentration, $[\mathrm{Tol}]_{S S}$. Finally, the UV lamp was turned off and the system equilibrated during a final $30 \mathrm{~min}$ period, at the end of which a final set of three samples was collected to verify that toluene concentrations were restored to the initial value. The initial (and final) toluene concentration, $[\mathrm{Tol}]_{0}$, was determined by averaging the results obtained in the initial and final phases, both with the UV lamp off. The reactor residence time was defined as:

$\tau=\frac{V}{f}$

where $V$ is the reactor volume (in $\mathrm{mL}$ ) and $f$ is the air flow rate (in $\mathrm{mL} \mathrm{min}^{-1}$ ). More formally, the residence time is defined as the first moment of the residence time distribution function, $E(t)$ [35]. Hence, the parameter defined by equation (16) would be more strictly described as space time, which is equal to the residence time only for gas phase reactions in which there is no pressure drop, isothermal operation and no change in the total number of moles. However, since these conditions are valid in our case, we use the term residence time (which is more commonly used in the UVPCO literature) instead of space time. Considering the very short residence times (between $\tau=120 \mathrm{~ms}$ and $\tau=1920 \mathrm{~ms}$ ), an equilibration period of 30 min was deemed sufficient to reach a steady-state situation under illumination and dark conditions. 


\subsection{Sampling and analysis}

Integrated toluene samples were collected in Tenax TA ${ }^{\circledR}$ sorbent tubes during periods of $\sim 5 \mathrm{~min}$ each at a flow rate of $20-80 \mathrm{~mL} \mathrm{~min}^{-1}$, corresponding to volumes in the range $100-1000 \mathrm{~mL}$. Samples were analyzed by thermal desorption gas chromatography with mass selective detection (TD/GC/MS), following the US EPA standard method TO-1 [36]. Analysis was carried out in an Agilent GC/MS Model 6890/5973 operated in the electron impact mode, and interfaced to a thermal desorption inlet with an autosampler (TDS 3, TDS A, Gerstel, Germany). A calibration curve for toluene in the range 5-150 ng was used for quantification, using 1-bromo-4-fluorobenzene as internal standard.

Formaldehyde was collected at the reactor outlet by in-situ derivatization using (DNPH)-coated silica cartridges (Waters, MA). The cartridges were preceded by ozone scrubbers to eliminate all traces of ozone formed under UV irradiation. DNPH cartridges were extracted with 2-mL carbonyl-free acetonitrile and analyzed by HPLC with UV detection at $360 \mathrm{~nm}$, following the US EPA Standard Method TO-11 [37].

\section{Results and Discussion}

\subsection{Effect of air flow rate and residence time on toluene removal}

The toluene removal (i.e., the conversion of toluene in the reactor) in each test, $X$, was calculated as a percent fraction:

$$
X=\left(1-\frac{[\mathrm{Tol}]_{S S}}{[\mathrm{Tol}]_{0}}\right) \times 100
$$

The dependence of $X$ on the flow rate and on the residence time is shown in Figure 3 for the two different reactor lengths considered in this study $(L=5$ and $10 \mathrm{~cm})$. All the experiments shown in Figure 2 were carried out at $\mathrm{RH}=10 \%$, at which we observed the maximum reactivity (vide infra, section 3.2). 

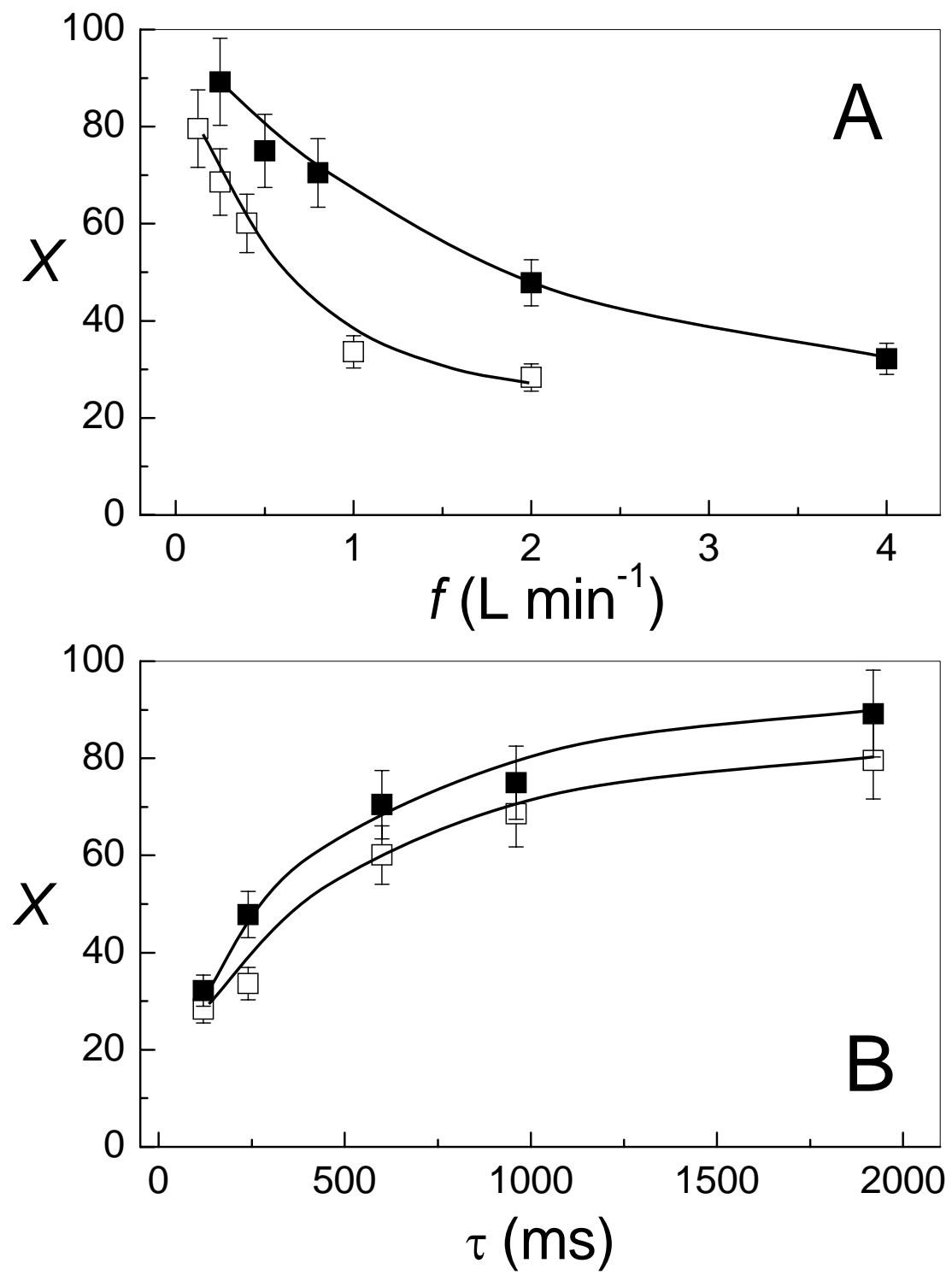

Figure 3. Toluene removal $(X)$ for two different reactor lengths $L=5 \mathrm{~cm}$ (white squares) and $L=10 \mathrm{~cm}$ (black squares), as a function of: (A) flow rate, $f$; (B) residence time, $\tau$.

The experimental conditions are reported in Table 3. Initial toluene concentrations, $[\mathrm{Tol}]_{0}$, were in the range $10-500 \mathrm{ppbv}$, as determined by the dilution of the primary toluene source required to achieve the desired total flow rate. Flow rates varied between 4 and $0.125 \mathrm{~L} \mathrm{~min}^{-1}$, and residence times spanned from $\tau=120$ to $1920 \mathrm{~ms}$. In that range, the toluene conversion efficiency increased from $\sim 30$ to $90 \%$, indicating that, under all the experimental conditions, the system did not achieve complete conversion. Previous studies showed that at such low toluene concentrations, the removal efficiency was shown to be 
independent of the initial concentration $[13,15]$ which suggested low coverage of the catalyst surface and first-order dependence on toluene concentration. In our case, for a given flow rate, the removal efficiency observed at the longest reactor length $(L=10 \mathrm{~cm})$ was significantly higher than that observed for $L=5 \mathrm{~cm}$ (Figure 3-A). However, at equal residence time and different toluene concentrations, we observed only a marginal increase in $X$ when the reactor length was doubled (Figure 3-B), which suggests that the reactor is effectively behaving as an ideal reactor in terms of flow and mixing conditions, and that the reaction is first-order in the concentration of toluene. The slight difference between the two curves should be attributed to the effect of the developing flow in the region near the reactor inlet and the first catalyst ring, which will affect more significantly the shorter reactor (smaller conversion) than the longer one. However, the length of this initial region is estimated to be small compared to the total length of each reactor since the difference between the two curves is only $\sim 10 \%$ or less, comparable to the average experimental error on $\mathrm{X}$. The observed increase in conversion with residence time is consistent with previously reported results [14]. The observed first-order reaction is consistent with the limiting case of a langmuirian rate equation of toluene oxidation when the concentration of toluene approaches very low values. However, in the present system, it should be observed that the reaction of toluene also occurs in the gas phase (see below), so the overall reaction cannot be attributed only to a heterogeneous reaction on the surface of the photocatalyst but to a contribution of both homogeneous and interfacial processes.

Table 3. Experimental conditions: reactor length $L$, initial toluene concentration $[\mathrm{Tol}]_{0}$, air flow $f$ and reactor residence time $\tau$.

\begin{tabular}{lccccc}
\hline \multicolumn{7}{c}{$\boldsymbol{L}=\mathbf{5} \mathbf{~ c m}$} \\
\hline$\left[\mathrm{Tol}_{\mathbf{0}}(\mathrm{ppbv})\right.$ & 32 & 84 & 152 & 365 & 479 \\
$\boldsymbol{f}\left(\mathrm{L} \mathrm{min}^{-1}\right)$ & 2.00 & 1.00 & 0.40 & 0.25 & 0.125 \\
$\tau(\mathrm{ms})$ & 120 & 240 & 600 & 960 & 1920 \\
\hline \multicolumn{5}{c}{$\boldsymbol{L}=\mathbf{1 0} \mathbf{~ c m}$} \\
\hline$\left[\mathrm{Tol}_{\mathbf{0}}(\mathrm{ppbv})\right.$ & 16 & 40 & 79 & 155 & 257 \\
$\left.\boldsymbol{f}(\mathrm{L} \mathrm{min})^{-1}\right)$ & 4.00 & 2.00 & 0.80 & 0.50 & 0.25 \\
$\tau(\mathrm{ms})$ & 120 & 240 & 600 & 960 & 1920 \\
\hline \hline
\end{tabular}




\subsection{Effect of the relative humidity on toluene removal}

The effect of relative humidity was evaluated for two of the experimental conditions described above, in order to consider cases with low and high toluene conversion:

a) $\quad$ low $X: L=5 \mathrm{~cm}$ and $f=1 \mathrm{~L} \mathrm{~min}^{-1}$, corresponding to a residence time of $240 \mathrm{~ms}$;

b) high $X: L=10 \mathrm{~cm}$ and $f=500 \mathrm{~mL} \mathrm{~min}^{-1}$, generating a residence time of 960 ms (i.e., 4 times longer).

Considering that conversion and residence time are independent of reactor length (i.e., apparent first-order kinetics) and assuming that intermediate byproducts have a negligible effect on the kinetics, the average toluene removal rate per unit reactor length, $T_{r}$, can be expressed as:

$\operatorname{Tr}=\frac{f}{L}\left([\mathrm{Tol}]_{0}-[\mathrm{Tol}]_{\mathrm{ss}}\right)$

Equation 18 also assumes that the average reaction rate is constant all throughout the experiment, with minimal catalyst inactivation. This assumption is reasonable considering the short duration of the irradiation (30-45 min) and the low toluene concentrations (in the $\mathrm{ppb}$ range). For much higher concentrations (in the hundreds of ppm), rapid inactivation of the photocatalyst has been reported [38].

Figure 4 shows the average reaction rates $T_{r}$ determined as a function of $\mathrm{RH}$ for both series of experiments. In either case, the reaction was faster at 10\% RH than under dry air, suggesting a positive contribution of low levels of water vapor on the kinetics. As RH increased further to $33 \%$ and $66 \%$, the net effect was an inhibition that led to reaction rates lower than those measured with dry air. The effect of low levels of water can be interpreted as a contribution of adsorbed water to the regeneration of active surface species at low water coverage (i.e., $10 \% \mathrm{RH}$ ), since $\mathrm{H}_{2} \mathrm{O}$ molecules adsorb dissociatively to $\mathrm{TiO}_{2}$ surfaces at low $\mathrm{RH}$, generating surface $\mathrm{OH}$ groups $[39,40]$. For $\mathrm{RH}>15-20 \%$, the amount of water adsorbed on the surface of $\mathrm{TiO}_{2}$ amounts to more than a monolayer [41], and the net effect is likely a competition with toluene for adsorption to the active surface sites that leads to a 
decline in toluene reaction rates with increasing RH. Competitive desorption of toluene from $\mathrm{TiO}_{2}$ surfaces in the dark upon increased water vapor has been described by Demeestere et al. (2003), who observed equilibrium adsorption coefficient reductions of up to one order of magnitude when RH increased from 0 to $58 \%$ [34].

Figure 4 also includes results obtained under identical flow conditions with uncoated Raschig rings, to estimate the contribution of non-photocatalytic processes to the overall reaction. For both residence times, we observed a significant reaction of toluene in the absence of $\mathrm{TiO}_{2}$, amounting to between a quarter and half of the toluene loss observed in the presence of the photocatalyst. This can be attributed to gas phase reactions with active oxygen species formed upon UVC irradiation (equations 4-11), as well as to direct photolysis of the aromatic molecule, particularly at low $\lambda\left(\varepsilon_{185 \mathrm{~nm}}=43,200 \mathrm{M}^{-1} \mathrm{~cm}^{-1} ; \varepsilon_{254 \mathrm{~nm}}\right.$ $\cong 100 \mathrm{M}^{-1} \mathrm{~cm}^{-1}$ ) [42]. The non-photocatalytic reactions rates also increased upon increasing RH from 0 to $10 \%$ (particularly in the case of the longer residence time), indicating additional contribution by $\mathrm{OH}^{\bullet}$ radicals formed by photolysis of water molecules as indicated by equations $8-11$. However, $T_{r}$ decreased with added water vapor at $33 \%$ and $66 \% \mathrm{RH}$, showing almost no significant differences between long and short residence times. Additional tests performed in $\mathrm{N}_{2}$ atmosphere (not included in Figure 3) showed a similar toluene removal rate as shown in the absence of the photocatalyst under dry air, suggesting that direct toluene photolysis was the predominant non-photocatalytic chemical process. 


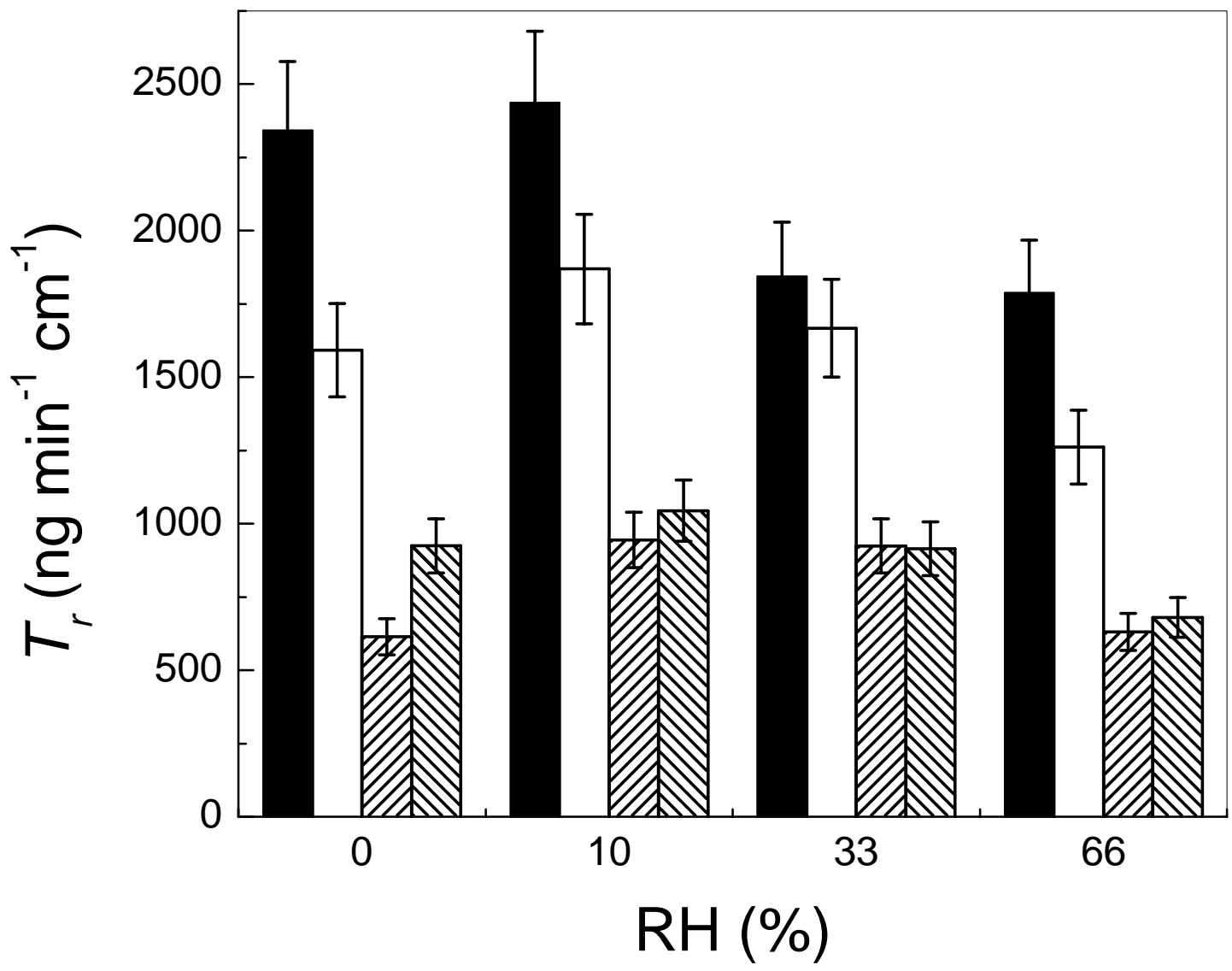

Figure 4. Reaction rate per unit reactor length, $T r$, as a function of relative humidity, RH. Black bars: $L=10 \mathrm{~cm}, f$ $=500 \mathrm{~mL} \mathrm{~min}{ }^{-1}, \tau=960 \mathrm{~ms}$; White bars: $L=5 \mathrm{~cm}, f=1 \mathrm{~L} \mathrm{~min}^{-1}, \tau=240 \mathrm{~ms}$; Striped bars $(/ / /) L=10 \mathrm{~cm}, f=500$ $\mathrm{mL} \min ^{-1}, \tau=960 \mathrm{~ms}$ in the absence of photocatalyst; Striped bars (III) $L=5 \mathrm{~cm}, f=1 \mathrm{~L} \mathrm{~min}^{-1}, \tau=240 \mathrm{~ms}$ in the absence of photocatalyst.

Our observations of optimal humidity conditions around $10 \% \mathrm{RH}$ for the degradation of low concentrations of toluene in the presence and in the absence of photocatalyst are consistent with results reported by other researchers. The photocatalytic oxidation of toluene at $500 \mathrm{ppb}$ and $290 \mathrm{ppb}$ was shown to peak for $\sim 2000 \mathrm{ppm} \mathrm{H}_{2} \mathrm{O}$ (equivalent to $\sim 10 \% \mathrm{RH}$ ) [43]. Sleiman et al. [15] observed the same inhibition of toluene photocatalytic oxidation at high $\mathrm{RH}$ using $\mathrm{TiO}_{2}$ supported in a paper matrix, with $\sim 100 \%$ conversion for all experiments performed at $\mathrm{RH}<20 \%$. Van Durme et al.[44] described a maximum degradation rate for $500 \mathrm{ppb}$ of toluene vapor at $26 \% \mathrm{RH}$ for its oxidation by non-thermal plasma (an emerging, complementary technology for gas phase photocatalytic air purification), but the processes under dry air and higher humidity conditions were less 
efficient. However, this effect cannot be generalized to other organic pollutants and/or to other experimental conditions. For example, Thevenet et al. [45] reported a continuous reduction in the reaction rate as $\mathrm{RH}$ increased for the oxidation of high levels of acetylene (thousands of ppm), both for photocatalytic oxidation and for non-thermal plasma methods.

\subsection{Effect of reactor parameters on the formaldehyde yield}

Formaldehyde is produced as a partial oxidation byproduct in the photocatalytic oxidation of toluene $[12,15]$. However, experimental conditions may be conducive to very different formaldehyde yields. The latter effect has not been systematically explored, and it is a critical aspect in the development of effective air cleaners. We define the formaldehyde molar overall yield $Y_{F}$ as:

$Y_{F}=\left(\frac{[F]_{S S}}{[\mathrm{Tol}]_{0}-[\mathrm{Tol}]_{S S}}\right) \times 100$

where $[F]_{\mathrm{ss}}$ is the formaldehyde concentration at the reactor outlet determined at steadystate during irradiation. In equation (19), all concentrations are expressed in $\mathrm{mol} \mathrm{L}^{-1}$. In Figure $5, Y_{\mathrm{F}}$ is represented as a function of $\mathrm{RH}$, in the range $0-66 \%$ for two different conditions. Two sets of experiments were carried out at the experimental conditions $\boldsymbol{a}$ and $\boldsymbol{b}$ described above, respectively, in order to explore conditions of low and high residence times. 


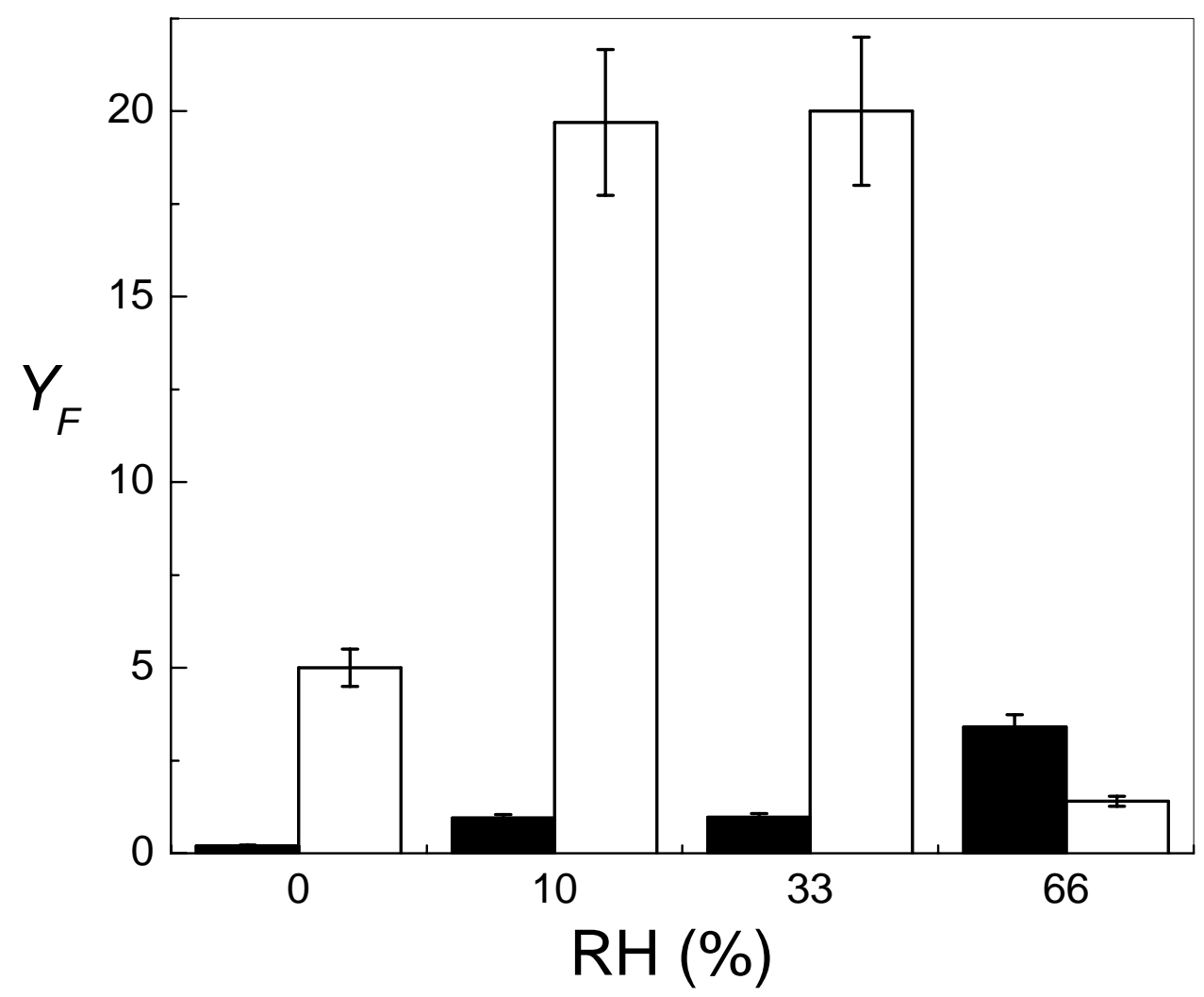

Figure 5. Formaldehyde yield $Y_{\mathrm{F}}$ as a function of RH. Data shown for: $L=5 \mathrm{~cm} ; f=1 \mathrm{~L} \mathrm{~min}^{-1} ; \tau=240 \mathrm{~ms}$ (white bars), and for: $L=10 \mathrm{~cm} ; f=500 \mathrm{~mL} \mathrm{~min}^{-1} ; \tau=960 \mathrm{~ms}$ (black bars).

Formaldehyde yield was highly dependent on the relative humidity, particularly for the experiment carried out at short residence time, in which $Y_{\mathrm{F}}$ reached values as high as $\sim 20 \%$ for intermediate RH levels (10\% and 33\%). Instead, dry air conditions did not favor the formation of formaldehyde in either case, suggesting that the presence of surface $\mathrm{OH}$ groups may play an important role in the pathways leading to formation of this byproduct, presumably through oxidative cleavage of the methyl group (side chain), as opposed to the oxidation of the aromatic ring [46]. The population of surface $\mathrm{OH}$ is regenerated through dissociative chemisorption of water vapor under humidified air, thus becoming a limiting factor under dry air $[39,40,43]$. On the other side, the multilayer water film formed at $66 \%$ RH on the surface of the photocatalyst [41] has the potential capacity to retain larger amounts of polar oxidation byproducts and reduce their gas-phase levels. These arguments may justify in qualitative terms the observation of maximum $Y_{\mathrm{F}}$ for intermediate humidity conditions at low residence time. With a 4-fold increase in $\tau, Y_{\mathrm{F}}$ was reduced at all $\mathrm{RH}$ 
conditions. Since toluene conversion was higher at $\tau=1.2 \mathrm{~s}$ than at $\tau=300 \mathrm{~ms}$ across the RH range (see Figure 3), it is reasonable to assume that formaldehyde oxidation proceeded also to a larger extent at the longer residence time, allowing for a more complete elimination of this intermediate byproduct.

These results can be compared with those from a previous study of the performance of a full-size UVPCO prototype [12], in which we determined a $Y_{\mathrm{F}}=16 \%$ for the reaction of $28 \mathrm{ppbv}$ of toluene at $47 \% \mathrm{RH}$. The UVPCO reactor consisted of two $30 \times 30 \mathrm{~cm}$ honeycomb monoliths of $2.5 \mathrm{~cm}$ length each, operating at a flow of $752 \mathrm{~m}^{3} \mathrm{~h}^{-1}$. The effective residence time of toluene vapor in the monoliths was $\tau=21 \mathrm{~ms}$. In that experiment, the much higher air flow determined a residence time one order of magnitude shorter than in the bench-scale experiment with the short $\tau$. Our results suggest that increasing the contact time between the target pollutant and the photocatalyst could produce significant improvements in terms of reduction of byproduct emissions, which is one of the major limitations of UVPCO air cleaners. Longer contact times of the target compounds (and their harmful oxidation byproducts) with the surface may be increased by altering the engineering of the air cleaner (for example using recirculation loops), but also through the introduction of nanostructured photocatalysts with significantly higher surface area, and/or photocatalysts supported on matrices with high surface area [27,31]. A higher adsorption capacity can contribute to retaining the target compound for a longer exposure time at the catalyst surface.

\subsection{Effect of $\mathrm{TiO}_{2}$ film thickness on toluene removal}

The effect of the $\mathrm{TiO}_{2}$ thickness was evaluated for the same two sets of reactor parameters $\boldsymbol{a}$ and $\boldsymbol{b}$ described above, using five different ring samples, each coated a different number of times, with different thickness. Description of these coated ring samples is given in Table 2, and experimental results are presented in Figure 6. For both residence times, we observed an initial increase of toluene conversion as the photocatalyst thickness increased from 100 to $500 \mathrm{~nm}$. A similar increase in the photocatalytic performance of thin films in the range $100-350 \mathrm{~nm}$ was reported by Addamo et al. for the degradation of 2-propanol [47]. The increased performance with respect to film thickness 
was more marked for the experiment performed at the short residence time: $X$ showed a 3fold increase (between 11.5 and 35\%) in the short residence time experiment, but it only increased $\sim 25 \%$ (from 67 to $85 \%$ ) in the long residence time experiment since the conversion of toluene was already high for the thinner films. However, as observed in Figure 6, at a certain film thickness (above $350 \mathrm{~nm}$ ), the conversion appears to reach a plateau. Finally, at thicknesses higher than $500 \mathrm{~nm}$, the conversion appears to drop. These results highlight the critical importance of controlling the thickness of the photocatalyst film, particularly when operating at the low residence times typical of building heating, ventilation and air conditioning (HVAC) systems.

The increase of the toluene conversion with the increase of the film thickness is consistent with a system in which the entire mass of the catalyst is effectively irradiated with UVC photons and in which transport of reactant by diffusion through the porous photocatalytic film is not limiting. However, in a supported "thick" photocatalytic film, the reaction space is confined to the region effectively irradiated; therefore, if the film is thick, only a small portion of it, close to the surface, may be effectively irradiated with photons, rendering the deeper portion of film inactive. In addition, internal diffusion of the reactant may also influence the reactivity. Both transport of photons and diffusion hinder the reactivity and conversion, the extent of these limitations being determined by the "effectiveness factor" [48], defined as:

$$
\eta=\frac{\text { observed reaction rate }}{\text { reaction rate at surface concentration and surface photon flux }}
$$

The optical thickness and the ratio of the characteristic diffusion time over reaction time affect the value of the effectiveness factor and, therefore, the extent of the limitations imposed by the geometry of the catalyst. These two independent factors are measured by the Thiele modulus $(\phi)$ of the film, which for a first-order surface reaction on both the concentration of toluene and the photon flow is given by Camera-Roda and Santarelli [48], in analogy with conventional catalysis in porous catalytic particles:

$$
\phi=\delta \sqrt{k P_{0}^{\lambda} k_{a} / D_{e}}
$$


where $\delta$ is the geometrical thickness of the film, $k$ is the first-order kinetic constant, $P_{\lambda}{ }^{0}$ is the initial spectral radiant power at the surface of the photocatalytic film, $k_{\mathrm{a}}$ is the absorption coefficient of the film at the wavelength of the incident radiation, and $D_{\mathrm{e}}$ is the effective diffusivity of the limiting reactant through the porous structure of the film. This analysis was developed originally for plane films, but we extend the conclusions of that study to the case of curved ring surfaces used in our case.

Multiple coatings of the same substrate imply multiple heating cycles of the $\mathrm{TiO}_{2}$ layers deposited in a sequence. As a result, it is not unconceivable to imagine that the porosity of the photocatalytic films may be reduced after each deposition. This progressively decreases the value of $D_{\mathrm{e}}$ through each inner layer and therefore produces the increase of the Thiele modulus, with the consequent limitation on the reaction rate.

In parallel, a progressively less porous structure of the film in the transversal direction may result in smaller value of $k_{a}$ (i.e., larger values of the Thiele modulus) since photon transport by forward scattering through the porous structure of the film may be progressively suppressed. Data on coatings vs. film thickness and UV absorbance by Choi et al., (2006) support smaller values of $k_{a}$ as the number of coatings was increased.

Finally, Figure 6 shows that at thickness higher than $500 \mathrm{~nm}$ the conversion appears to drop. According to the experimental results, it can be suggested that the "effectiveness factor" is less than the unity at a thickness of the film higher than $350 \mathrm{~nm}$. The increase in the Thiele modulus by a progressive reduction of the porosity of the film explains also the drop in conversion observed for the sample with a film thickness of $635 \mathrm{~nm}$. Other factors may be at play at higher thickness leading to reactivity losses, such as, for example, effects related to curved substrate surfaces leading to diverse irradiation angles, as compared with the flat surfaces modeled by Camera-Roda and Santarelli [48]. 


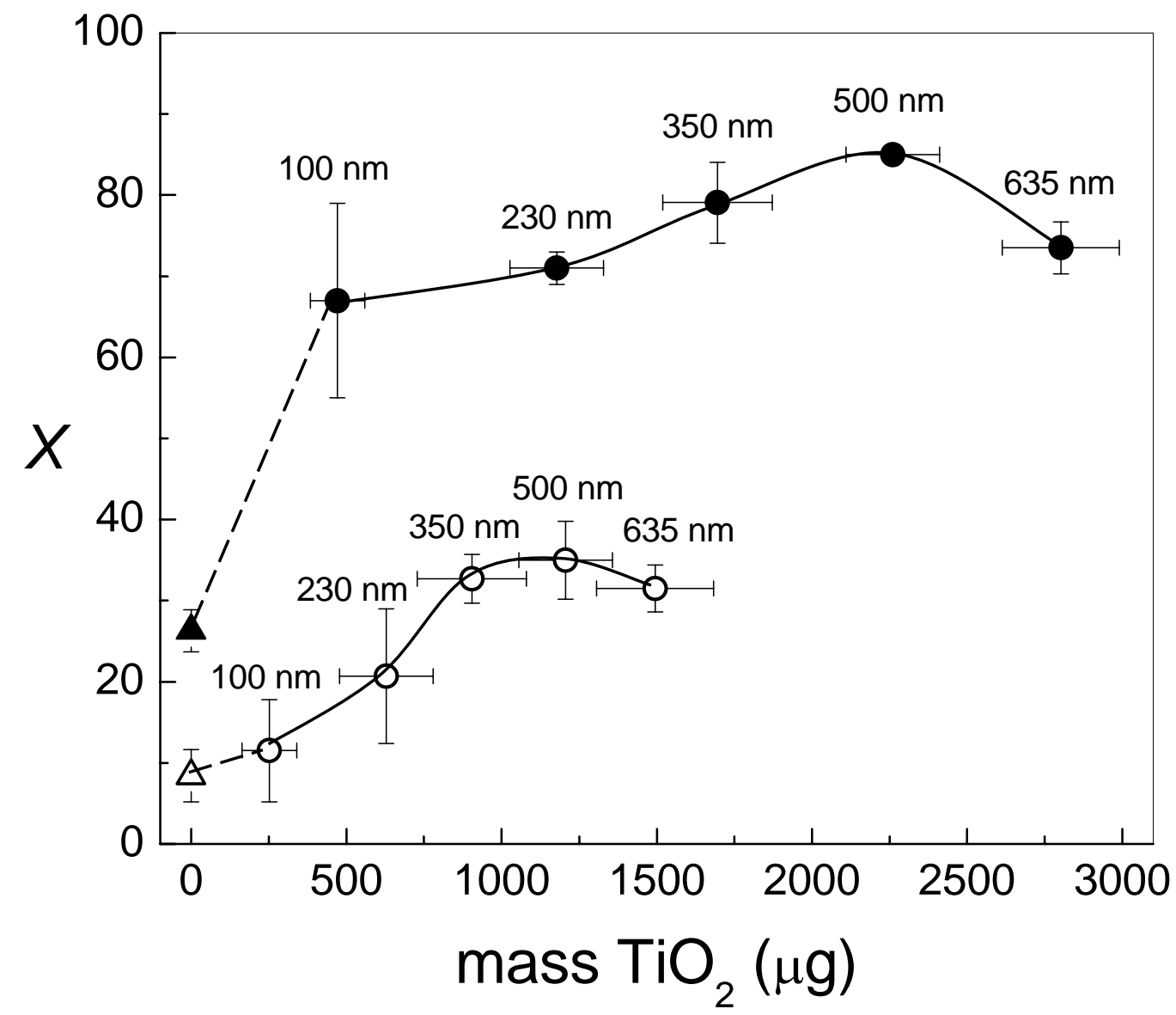

Figure 5: Toluene conversion, $X$, under dry air as a function of the mass of photocatalyst coating. The thickness of the photocatalyst film is indicated for each experimental data point. White data points: $L=5 \mathrm{~cm}, f=1 \mathrm{~L} \mathrm{~min}^{-1}, \tau=$ $240 \mathrm{~ms}$. Black data points: $L=10 \mathrm{~cm}, f=500 \mathrm{~mL} \mathrm{~min}^{-1}, \tau=960 \mathrm{~ms}$. Triangular points represent $X$ for experiments carried out with uncoated rings.

\section{Conclusions}

Our results illustrate the effect of key parameters on the performance of $\mathrm{TiO}_{2}$ films irradiated with UV light of $254+185 \mathrm{~nm}$ in the photocatalytic degradation of toluene, and the interplay between some of these parameters. Experiments were carried out at realistic toluene concentrations (ppb range), with conversions $X$ in the range 30-90\%. Low coverage of the catalyst surface with toluene and first-order dependence on toluene concentration were observed consistent with the limiting case of a langmuirian-type rate equation of toluene oxidation when the concentration of toluene approaches very low values. Relative 
humidity clearly influenced toluene removal efficiency, and both RH and $\tau$ affected dramatically the yield of formaldehyde, an intermediate byproduct. These results highlight the importance of controlling these parameters in air cleaning operations in order to minimize the impact of undesired byproducts. Additionally, the thickness of the $\mathrm{TiO}_{2}$ film can be finely tuned to maximize the removal efficiency while avoiding the inhibitory effect observed for thick photocatalyst films. The limitations imposed by radiation transport and reactant diffusion in thick photocatalytic films may be alleviated by preparation techniques which would not change the porous structure of the supported catalyst in multiple coatings, such as using hydrothermal sol-gel method or low temperature anchoring methods.

\section{Acknowledgements}

The authors express gratitude to R. Maddalena and M. Russell (LBNL) for GC/MS support. Experimental work was carried out at LBNL under US DOE Contract No. DEAC02-05CH1 1231. This project was supported by a LBNL's Laboratory Directed R\&D Project (\# 08-103, ID 366088), and by the Agencia Nacional de Promoción Científica y Tecnológica (ANPCyT) project PICT2003-13-13261 (Argentina). N. Quici thanks CNEACONICET for a doctoral fellowship. D.D. Dionysiou acknowledges funding from the National Science Foundation through a CAREER Award (BES-0448117) for studies dealing with the synthesis of sol-gel $\mathrm{TiO}_{2}$ materials.

\section{References}

[1] M.J. Mendell, W.J. Fisk, K. Kreiss, H. Levin, D. Alexander, W.S. Cain, J.R. Girman, C.J. Hines, P.A. Jensen, D.K. Milton, L.P. Rexroat, K.M. Wallingford, Am. J. Pub. Health 92 (2002) 1430-1440.

[2] M.J. Mendell, Indoor Air 17 (2007) 259-277.

[3] US DOE, Buildings energy data book (2006), US Department of Energy. Washington DC (http://buildingsdatabook.eren.doe.gov)..

[4] M.R. Hoffmann, S.T. Martin, W. Choi, D.W. Bahnemann, Chem. Rev. 95 (1995) 69-96.

[5] O. D'hennezel, P. Pichat, D.F. Ollis, J. Photochem. Photobiol., A 118 (1998) 197-204.

[6] D.F. Ollis, C. R. Acad. Sci. Paris - Chemistry 3 (2000) 405-411. 
[7] P. Pichat, J. Disdier, C. Hoang-van, D. Mas, G. Goutailler, C. Gaysse, Catal. Today 63 (2000) 363-369.

[8] P. Pichat, Photocatalytic degradation of pollutants in water and air: basic concepts and applications, in Chemical degradation methods for wastes and pollutants: environmental and industrial applications, M.A. Tarr, Marcel Dekker, New York (2003).

[9] B. Sanchez, A.I. Cardona, J. Peral, M. I. Litter, Gas purification by heterogeneous photocatalysis, in Waste gas treatment for resource recovery (2006), Edit: P.N.L. Lens, IWA Publishing, London. (ISBN: 1843391279, Cap. 13, p. 195-225).

[10] R. Atkinson, S.M. Aschmann, Int. J. Chem. Kinet. 21 (1989) 355-365.

[11] C.H. Ao, S.C.Lee, J.Z. Yu, J.H. Xu, Appl. Catal. B 54 (2004) 41-50.

[12] A.T. Hodgson, H. Destaillats, T. Hotchi, W.J. Fisk (2007). Evaluation of a combined ultraviolet photocatalytic oxidation (UVPCO) / chemisorbent air cleaner applications.

LBNL Report \# 62202 (http://repositories.cdlib.org/lbnl/LBNL-62202/).

[13] A.T. Hodgson, H. Destaillats, D. Sullivan, W.J. Fisk, Indoor Air 17 (2007) 305-316.

[14] K. Demeestere, J. Dewulf, B. De Wittle, A. Beeldens, H. Van Langenhove, Building and Environment 43 (2008) 406-414.

[15] M. Sleiman, P. Conchon, C. Ferronato, J-M. Chovelon, Appl. Catal. B 86 (2009) 159165.

[16] L.Yang, Z. Liu, J. Shi, Y.Zhang, H. Hu, W Shangguan, Sep. Purif. Technol. 54 (2007) 204-211.

[17] J. Jeong, K. Sekiguchi, W. Lee, K. Sakamoto, J. Photochem. Photobiol., A 169 (2005) 279-287.

[18] J. Jeong, K. Sekiguchi, K. Sakamoto, Chemosphere 57 (2004) 663-671.

[19] K.-P. Yu, G.W.M. Lee, Appl. Catal. B 75 (2007) 29-38.

[20] W. Wang, L.-W. Chiang, Y. Ku, J. Hazard. Mat. B101 (2003) 133-146.

[21] A. Mizuno, Plasma Phys. Controlled Fusion 49 (2007) A1-A15.

[22] A. Mizuno, Y. Kisanuki, M. Noguchi, S. Katsura, S.H. Lee, Y.K. Hong, S.Y. Shin, J.H. Kang, IEEE Trans. Indust. Appl. 35 (1999) 1284-1288.

[23] H.B. Huang, D.Q. Ye, M.L. Fu, F.D. Feng, Plasma Chem. Plasma Process 27 (2007) 577-588.

[24] M. Okubo, T. Yamamoto, T. Kuroki, H. Fukumoto, IEEE Trans. Indust. Appl. 37 (2001) 1505-1511. 
[25] B. J. Finlayson-Pitts, J. N. Pitts, Chemistry of the Upper and Lower Atmosphere (2000), Academic Press, San Diego.

[26] R.J. Cvetanovic, J. Phys. Chem. Ref. Data 16 (1987) 261-326.

[27] D. Kibanova, J. Cervini-Silva, H. Destaillats, Environ. Sci. Technol., 43 (2009) 15001506.

[28] S. Toby, L.J. Van der Burgt, F.S. Toby, J. Phys. Chem. 89 (1985) 1982-1986.

[29] V. Augugliaro, M. Litter, L. Palmisano, J. Soria, J. Photochem. Photobiol., C 7 (2006) $127-144$.

[30] Y. Luo, D.F. Ollis, J. Catal. 163 (1996) 1-11.

[31] D. Kibanova, M. Trejo, H. Destaillats, J. Cervini-Silva, Appl. Clay Sci. 42 (2009) 563568 .

[32] H. Choi, E. Stathatos, D.D. Dionysiou, Appl. Catal. B 63 (2006) 60-67.

[33] M.L. Vera, Preparación de fotocatalizadores de $\mathrm{TiO}_{2}$ soportados para su uso en potabilización de aguas (Master Thesis), Instituto de Tecnología Prof. Jorge A. Sábato, Universidad Nacional de General San Martín, Argentina (2008).

[34] K. Demeestere, J. Dewulf, H. Van Langenhove, B. Sercu, Chem. Eng. Sci. 58 (2003) 2255-2267.

[35] H.S. Fogler, Elements of Chemical Reaction Engineering, $4^{\text {th }}$ Edition, Prentice Hall, New York, 2005 (p. 880).

[36] USEPA, Method TO-1, Revision 1,0: Method for the determination of volatile organic compounds in ambient air using Tenax(R) Adsorption and gas chromatography/mass spectrometry (GC/MS), Center for Environmental Research Information, Office of Research and Development US Environmental Protection Agency (1984).

[37] USEPA, Determination of formaldehyde in ambient air using adsorbent cartridge followed by high performance liquid chromatography (HPLC) [active sampling methodology], ed. Center for Environmental Research Information. Cincinnati, OH (1999). [38] H. Einaga, S. Futamura, T. Ibusuki, Appl. Catal. B 38 (2002) 215-225.

[39] S. Yamamoto, H. Bluhm, K. Andersson, G. Ketteler, H. Ogasawara, M. Salmeron, A. Nilsson, J. Phys.: Condens. Matter 20 (2008) 184025-184039.

[40] G. Ketteler, S. Yamamoto, H. Bluhm, K. Andersson, D.E. Starr, D.F. Ogletree, H. Ogasawara, A. Nilsson, M. Salmeron, J. Phys Chem. C 111 (2007) 8278-8282. [41] A.L. Goodman, E.T. Bernard, V.H. Grassian, J. Phys. Chem. A 105 (2001) 6443-6457. 
[42] H. Hippler, J. Troe, H.J. Wendelken, J. Chem. Phys. 78 (1983) 5451-5357.

[43] T. N. Obee, R.T. Brown, Environ. Sci. Technol. 29 (1995) 1223-1231.

[44] J. Van Durme, J. Dewulf, W. Sysmans, C. Leys, H. Van Langenhove,. Chemosphere 68 (2007) 1821-1829.

[45] F. Thevenet, O. Guaitella, E. Puzenat, C. Guillard, A. Rousseau, Appl. Catal. B 84 (2008) 813-820.

[46] T. Guo, Z. Bai, C. Wu, T. Zhu, Appl. Catal. B 79 (2008) 171-178.

[47] M. Addamo, V. Augugliaro, A. Di Paola, E. Garcia-Lopez, V. Loddo, G. Marci, L. Palmisano, Thin Solid Films 516 (2008) 3802-3807.

[48] G. Camera-Roda, F. Santarelli, Catal. Today 129 (2007)161-168. 